\title{
Involvement of tryptase-positive mast cells and angiogenesis in the growth of inflammatory odontogenic cysts
}

\author{
Hugo COSTA NETO(a) (iD \\ Ana Luiza Dias Leite de \\ ANDRADE(b) \\ Andréia Ferreira do CARMO(a) \\ Roseana de Almeida FREITAS(a) ID \\ Hébel Cavalcanti GALVÃO(a) \\ (a) Universidade Federal do Rio Grande do \\ Norte - UFRN, Department of Dentistry, \\ Natal, RN, Brazil. \\ (b) Universidade Federal de Alfenas - Unifal, \\ Department of Anatomy, Alfenas, MG, Brazil.
}

Declaration of Interests: The authors certify that they have no commercial or associative interest that represents a conflict of interest in connection with the manuscript.

Corresponding Author:

Hugo Costa Neto

e-mail: hugoneto.odonto@hotmail.com

https://doi.org/10.1590/1807-3107bor-202/1.vol35.0061

Submitted: May 20, 2020

Accepted for publication: October 22, 2010

Last revision: February 1, 2021
Abstract: Inflammatory periapical lesions are characterized by infiltration of different immune cell types, the functions of which depend on an effective vascular network. This study aimed to evaluate the mast cells density (MCD) in inflamatory odontogenic cysts capsules concerning microvascular density (MVD), microvascular area (MVA), and microvascular perimeter (MVP), and correlate such findings with the type of lesion, intensity of the inflammatory infiltrate, and thickness of the epithelial lining. Twenty inflamatory dentigerous cysts (IDCs), twenty radicular cysts (RCs), and twenty residual radicular cysts (RRCs) were submitted to immunohistochemical analysis using anti-tryptase and anti-CD34 antibodies. RCs exhibited the highest MCD, MVD, MVA, and MVP indexes $(p=<0.001, p=0.008, p=0.003$ and $p=<0.001$, respectively), and lesions with inflammatory infiltrate grade III showed the highest MVD ( $p=0.044)$. Considering epithelial thickness, a higher MVP index was identified in lesions with hyperplastic epithelium ( $p=0.018$ ). In IDCs, RCs, and RRCs, a strong positive correlation was observed between MVA and MVP $(r=0.950$ and $\mathrm{p}=<0.001$; $r=0.914$ and $p=<0.001 ; r=0.713$ and $p=<0.001$, respectively). In IDCs, a moderate correlation was observed between MCD and both MVA and MVP $(r=0.660$ and $p=0.002 ; r=0.634$ and $p=0.003$, respectively). These results suggest that tryptase-positive mast cells might play an important role in the angiogenic activity of IDCs, while RCs had the highest indexes. Our findings also confirmed that the intensity of the inflammatory infiltrate and epithelial thickness influence angiogenesis.

Keywords: Microvascular Density; Antigens, CD34; Mast Cells; Tryptases; Odontogenic Cysts.

\section{Introduction}

Odontogenic cysts are characterized by bone destruction, and they develop from odontogenic epithelium components or epithelial remnants that remain trapped in bone or gingival tissue. ${ }^{1}$ Radicular cysts (RCs) and dentigerous cysts (DCs) comprise the most frequent gnathic bone cystic lesions among odontogenic cysts. ${ }^{2,3}$

RCs arise as a result of periradicular tissue inflammation caused by bacterial agents and consequent pulp necrosis. ${ }^{4}$ Eventually, the RC-affected tooth is extracted with little consideration to the periapical pathology, 
which remains inside the maxillary bones as a residual radicular cyst $(\mathrm{RRC}) .^{5}$ Differently, DCs are developmental odontogenic cysts associated with impacted teeth. ${ }^{6}$ However, it has been suggested that periapical inflammation of non-vital deciduous teeth near the follicles of their respective unerupted permanent successors may trigger cystic formations known as inflammatory dentigerous cysts (IDC). ${ }^{7}$

Inflammation and the subpopulations of inflammatory cells are crucial for the development of the aforementioned lesions. ${ }^{4}$ These cystic inflammatory infiltrate components include, among others, mast cells, which are granular cells of hematopoietic origin. These cells, when activated in response to microbial products, secrete numerous cytoplasmic granules and lipid mediators, such as chymase and tryptase, which stimulate inflammation and are associated with different biological processes, such as vascular proliferation and vasodilation, within the lesion microenvironment, as well as tissue repair, allergies, and host defense mechanisms. ${ }^{8,9}$

Several studies have associated mast cells function to angiogenesis. Mast cells seem influence angiogenesis by the release of granular components after their degranulation. ${ }^{10,11,12}$ Angiogenesis is a complex, multi-stage process involving not only the formation of blood vessels, but also the proliferation and migration of endothelial cells. ${ }^{13,14}$ The use of immunohistochemical markers, such as Von Willebrand factor (vWF), CD31, CD105, and CD34, provides a measure of angiogenesis in a variety of pathological processes,$^{15}$ which may be influenced by inflammation. ${ }^{16}$

The present study aimed to evaluate CD34 and tryptase expressions in RC, RRC, and IDC capsules, concerning density and microvascular pattern through immunohistochemical analyses, regarding type of lesion, intensity of the inflammatory infiltrate, and thickness of the epithelial lining.

\section{Methodology}

\section{Study design and tissue samples}

Sixty specimens (20 DCs, 20 RCs, and 20 RRCs), stored in the Oral Pathology Department of the Federal University of Rio Grande do Norte (UFRN), were randomly selected. RCs showed a unilocular radiolucent area associated with a devitalized tooth without endodontic treatment. RRCs showed a radiolucent area at the site of an extracted tooth affected by a periapical lesion with histopathological diagnosis of RC. IDCs showed a unilocular radiolucent area associated with the crown of an unerupted vital tooth or attached to the tooth at the cementoenamel junction. Pathological diagnoses were confirmed based on clinical, radiographic, and histological well-defined criteria. The histological criterion was the presence of a pathological cavity covered predominantly or entirely by non-keratinized stratified squamous epithelium of varying thickness with underlying fibrous capsule presenting different degrees of inflammation. The study was approved by the Ethics Committee of UFRN, Natal, Brazil (protocol number: 1.177.393).

\section{Morphological analysis}

For morphological analysis, $5-\mu$ m-thick tissue sections were stained with hematoxylin and eosin. The intensity of inflammatory infiltrate was evaluated according to an adaptation of the method proposed by Tsai et al. ${ }^{4}$ Grading of each specimen was recorded on inflammatory condition in three consecutive microscopic fields, starting from the inner portion of the specimen and proceeding deeper into the connective tissue. Briefly, each specimen was graded at $\times 400$ magnification as: grade I, inflammatory cells restricted to the first microscopic field; grade II, inflammatory cells extending to the second microscopic field; and grade III, inflammatory cells in all three microscopic fields. The analysis of the epithelial lining thickness was performed considering all the cyst lining. Epithelial lining thickness was defined as atrophic (2-10 cell layers) or hyperplastic ( $>10$ cell layers), based on the predominant pattern in each case. ${ }^{17}$

\section{Immunohistochemical methods}

For the immunohistochemical study, tissue sections were deparaffinized and immersed in methanol with $0.3 \%$ hydrogen peroxide to block endogenous peroxidase activity. Tissue sections were then washed in phosphate-buffered saline (PBS). After treatment with normal serum, sections were incubated for $60 \mathrm{~min}$ and at $4^{\circ} \mathrm{C}$ overnight in a moist chamber with the 
primary antibody anti-tryptase (Dako Corporation ${ }^{\circledR}$, clone AA1, working dilution 1:200, Carpinteria, USA) and anti-CD34 (Cell Marque ${ }^{\mathrm{TM}}$, clone QBEnd 101, working dilution 1:200, Rocklin, USA), respectively. The sections were then washed twice in PBS and treated with streptavidin-biotin-peroxidase complex (LSAB; Dako, Glostrup, Denmark) at room temperature to bind the primary antibodies. Peroxidase activity was visualized by immersing the tissue sections in diaminobenzidine (D5637; Sigma Chemical, St. Louis, USA), resulting in a brown reaction product. Finally, tissue sections were counterstained with Mayer hematoxylin and coverslipped. Sections of neurofibroma and capillary hemangioma were used as positive control to tryptase and CD34, respectively. Negative control consisted of sections in which the primary antibody was omitted and replaced with either nonimmune murine IgG1 (X 0931; Dako) or $1 \%$ PBS-BSA.

\section{Immunostaining assessment}

Each specimen was analyzed under light microscopy (Olympus BX41, Olympus Japan Co., Tokyo, Japan) and, subsequently, the slides were scanned (Panoramic MIDI, 1:15 SPI, 3D HISTECH, Budapest, Hungary). First, histological sections from the same specimen, stained for respective anti-tryptase and anti-CD34 antibodies, were opened simultaneously in Panoramic Viewer 1.15.2 program (3D HISTECH, Budapest, Hungary), tiled horizontally, and synchronized by the slide window option to ensure the best approximation of same areas. Under 200x magnification (Panoramic MIDI, 1.15 SPI, 3D HISTECH, Budapest, Hungary), five representative and random fields were selected after identification of areas with the greatest immunoreactivity and images were analyzed using Imaging Processing and Analysis in Java (Image ${ }^{\circledR}$, National Institute of Mental Health, Bethesda, USA). Immunohistochemical expression of CD34 was determined to measure microvascular density (MVD), microvascular area (MVA), and microvascular perimeter (MVP) according to methodology adapted from the study by Lima et al. ${ }^{18}$ MVD was performed by counting positive blood vessels. For MVA and MVP, areas and perimeters of such structures were measured.
Individual endothelial cells or groups of endothelial cells, with or without a lumen, were considered as CD34-positive vessels when stained brown. Mast cell density (MCD) was assessed using anti-tryptase antibody and viewed under 200x magnification. For tryptase-positive mast cells identification, only cells with brownish intracytoplasmic staining were quantified. Subsequently, the mean number of marked cells in five photographed fields was determined.

\section{Statistical analysis}

The results were submitted to statistical analysis using the Statistical Package for the Social Sciences (version 20.0; SPSS Inc., Chicago, USA). After analysis for normality and variance of the data, the non-parametric Mann-Whitney and Kruskal-Wallis tests were applied. Spearman's correlation test was performed to determine possible correlations. For all tests, significance level was set at $5 \%(p<0.05)$.

\section{Results}

\section{Morphological analysis}

Analysis of inflammatory infiltrate in IDCs revealed that 13 cases (65.0\%) exhibited an inflammatory infiltrate grade III, and 7 cases (35.0\%), grade II (Figure 1A). In RCs, 19 cases (95.0\%) showed an inflammatory infiltrate grade III, and 1 case (5.0\%), grade II (Figure 1C). In RRCs, 7 cases (35.0\%) showed an inflammatory infiltrate grade III, 10 cases (50.0\%), grade II, and 3 cases $(15.0 \%)$, grade I (Figure 1B). Due to the scarcity of cysts with mild inflammation, cases with inflammatory infiltrates grades I and II were grouped.

Morphological analysis of epithelial thickness in IDCs and RCs revealed the presence of a hyperplastic epithelium in 13 cases $(65.0 \%)$ and an atrophic epithelium in 7 cases (35.0\%). In RRCs, 8 cases (40.0\%) presented a hyperplastic epithelium and 12 cases (60.0\%) showed an atrophic epithelium.

\section{Immunohistochemical analysis}

\section{Mast cells density}

Immunoexpression of tryptase was positive for all evaluated cases of IDCs, RRCs, and RCs (Figures D, $\mathrm{E}$ and $\mathrm{F}$, respectively). The mean MCD was 8.54 in 
Involvement of tryptase-positive mast cells and angiogenesis in the growth of inflammatory odontogenic cysts

IDCs, 18.05 in RCs, and 13.84 in RRCs. A significantly higher median number of tryptase-positive mast cells was identified in RRCs when compared to RCs and IDCs $(\mathrm{p}<0.001)$ (Table 1$)$.

Considering the intensity of the inflammatory infiltrate, the mean MCD was 15.02 in lesions with inflammatory infiltrate grade I / grade II, and 12.65 in lesions with grade III. No significant difference was observed between the groups ( $\mathrm{p}=0.381)$.

In relation to epithelial thickness, the mean MCD was 15.73 in lesions with hyperplastic epithelium and 20.65 in lesions with atrophic epithelium. No significant difference was verified between the groups $(p=0.163)$.

Table 1. Analysis of MCD, MVD, MVA, and MVP according to type of lesion, intensity of inflammatory infiltrate, and epithelial thickness.

\begin{tabular}{|c|c|c|c|c|c|c|c|c|c|}
\hline \multirow{3}{*}{ Variable } & \multirow{3}{*}{$\mathrm{n}$} & \multicolumn{2}{|c|}{ Mast cells density } & \multicolumn{2}{|c|}{ Microvascular density } & \multicolumn{2}{|c|}{ Microvascular area } & \multicolumn{2}{|c|}{ Microvascular perimeter } \\
\hline & & Mean \pm SD & \multirow{2}{*}{$\mathrm{p}$-value } & Mean \pm SD & \multirow{2}{*}{ p-value } & Mean \pm SD & \multirow{2}{*}{ - p-value } & Mean \pm SD & \multirow{2}{*}{$\mathrm{p}$-value } \\
\hline & & (n) & & (n) & & $\left(\mu \mathrm{m}^{2}\right)$ & & $(\mu \mathrm{m})$ & \\
\hline \multicolumn{10}{|l|}{ Type of lesion } \\
\hline Inflamed dentigerous cyst & 20 & $8.54 \pm 8.25$ & $<0.001^{*}$ & $24.00 \pm 12.42$ & $0.008^{*}$ & $2989.89 \pm 3030.44$ & $0.003^{*}$ & $333.84 \pm 146.69$ & $<0.001^{*}$ \\
\hline Radicular cyst & 20 & $18.05 \pm 10.28$ & & $34.99 \pm 15.54$ & & $3202.25 \pm 1974.46$ & & $400.00 \pm 145.25$ & \\
\hline Residual radicular cyst & 20 & $13.84 \pm 3.45$ & & $23.95 \pm 5.09$ & & $1488.54 \pm 817.17$ & & $225.64 \pm 79.58$ & \\
\hline \multicolumn{10}{|l|}{ Inflammatory infiltrate } \\
\hline Grade I / Grade II & 21 & $15.02 \pm 10.15$ & 0.381 & $22.36 \pm 5.02$ & $0.013^{*}$ & $2159.00 \pm 2244.29$ & 0.099 & $269.30 \pm 97.61$ & 0.093 \\
\hline Grade III & 39 & $12.65 \pm 7.77$ & & $30.49 \pm 14.71$ & & $2776.29 \pm 2237.31$ & & $347.03 \pm 159.51$ & \\
\hline \multicolumn{10}{|l|}{ Epithelial thickness } \\
\hline Hyperplastic epithelium & 34 & $15.73 \pm 10.21$ & 0.163 & $29.96 \pm 14.57$ & 0.061 & $2900.64 \pm 2347.46$ & 0.062 & $362.86 \pm 164.78$ & $0.018^{*}$ \\
\hline Atrophic epithelium & 26 & $20.65 \pm 12.93$ & & $24.61 \pm 9.38$ & & $2115.08 \pm 2051.44$ & & $263.56 \pm 89.11$ & \\
\hline
\end{tabular}
${ }^{*} p<0.05$
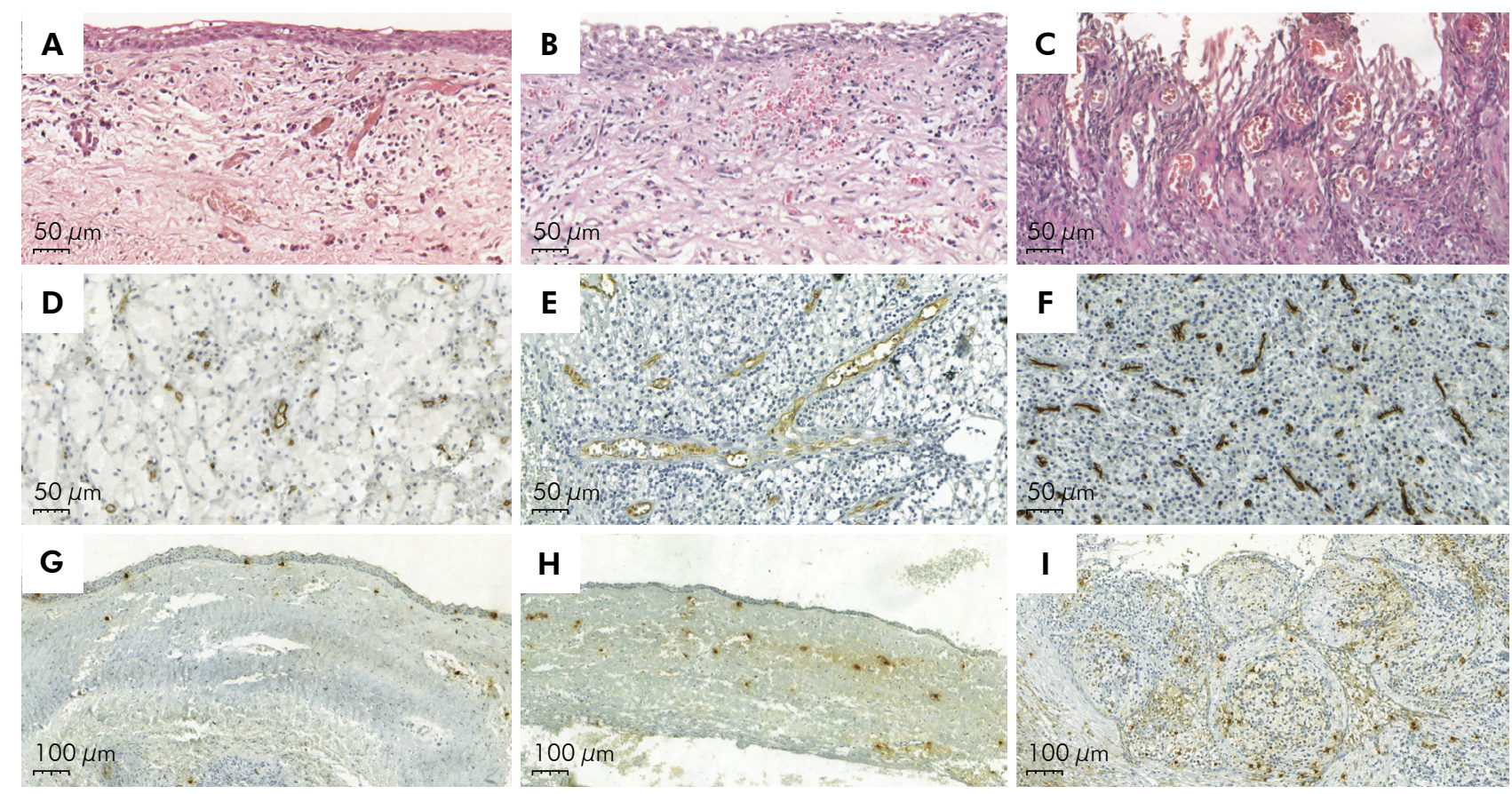

Figure. (A, B, C) Histopathological aspects of IDC, RRC, and RC, respectively. (D, E, F) Immunoexpression of tryptase in IDC, RRC, and $R C$, respectively. $(G, H, I)$ Immunoexpression of $C D 34$ in IDC, RRC and $R C$, respectively. 


\section{Microvascular density}

Analysis of immunoexpression showed CD34 positivity for all evaluated cases of IDCs, RRCs, and RCs (Figures 1G, H, I, respectively). The mean MVD was 24.00 in IDCs, 34.99 in RCs, and 23.95 in RRCs. A statistically significant higher median number of CD34-positive blood vessels was identified in RCs when compared to RRCs and IDCs $(p=0.008)$ (Table 1$)$.

Regarding the intensity of the inflammatory infiltrate, the mean MVD was 22.36 in lesions with inflammatory infiltrate grade I / grade II, and 30.49 in lesions with grade III. A statistically significant higher median number of CD34-positive blood vessels was identified in lesions with grade III when compared with those with grade I and II ( $p=0.013)$.

Considering the epithelial thickness, the mean MVD was 29.96 in lesions with hyperplastic epithelium and 24.61 in lesions with atrophic epithelium. No statistically significant difference was verified between the groups $(\mathrm{p}=0.061)$.

\section{Microvascular area}

The mean MVA was $2989.89 \mu \mathrm{m}^{2}$ in IDCs, $3202.25 \mu \mathrm{m}^{2}$ in RCs, and $1488.54 \mu \mathrm{m}^{2}$ in RRCs. A statistically significant higher median number of MVA was identified in IDCs and RCs when compared to RRCs $(p=0.003)$ (Table 1).

With respect to the intensity of the inflammatory infiltrate, the mean MVA was $2159.00 \mu \mathrm{m}^{2}$ in lesions with inflammatory infiltrate grade I / grade II, and $2776.29 \mu \mathrm{m}^{2}$ in lesions with grade III. No statistically significant difference was verified between the groups $(p=0.159)$.

Considering the epithelial thickness, the mean MVA was $2900.64 \mu \mathrm{m}^{2}$ in lesions with hyperplastic epithelium and $2115.08 \mu \mathrm{m}^{2}$ in lesions with atrophic epithelium. No statistically significant difference was verified between the groups $(p=0.062)$.

\section{Microvascular perimeter}

The mean MVP was $333.84 \mu \mathrm{m}$ in IDCs, $400.00 \mu \mathrm{m}$ in RCs, and $225.64 \mu \mathrm{m}$ in RRCs. A statistically significant higher median number of MVP was identified in IDCs and RCs when compared to RRCs $(p<0.001)$ (Table 1$)$.

With respect to intensity of inflammatory infiltrate, the mean MVP was $269.30 \mu \mathrm{m}$ in lesions with inflammatory infiltrate grade I / grade II, and $347.03 \mu \mathrm{m}$ in lesions with grade III. No statistically significant difference was verified between the groups $(p=0.174)$.

Considering the epithelial thickness, the mean MVP was $362.86 \mu \mathrm{m}$ in lesions with hyperplastic epithelium and $263.56 \mu \mathrm{m}$ in lesions with atrophic epithelium. A statistically significant higher median number of MVP was identified in lesions with hyperplastic epithelium when compared with those with atrophic epithelium $(p=0.018)$.

Correlation between MCD, MVD, MVA, and MVP

In IDCs, Spearman's correlation test showed strong positive correlation between MVA and MVP $(\mathrm{r}=0.950 ; \mathrm{p}=<0.001)$, and moderate positive correlation between MCD and MVA ( $r=0.660 ; p=0.002)$ and between MCD and MVP ( $r=0.634 ; p=0.003)$. In RCs and RRCs, a strong positive correlation was observed between MVA and MVP ( $\mathrm{r}=0.914 ; \mathrm{p}<0.001$ and $r=0.713 ; p<0.001$, respectively) (Table 2).

Table 2. Spearman's correlation test between MCD, MVD, MVA, and MVP, according to type of lesion.

\begin{tabular}{|c|c|c|c|}
\hline Type of lesion & $\mathrm{n}$ & $r$ & $p$-value \\
\hline \multicolumn{4}{|c|}{ Inflamed dentigerous cyst } \\
\hline$M C D \times M V D$ & 20 & 0.129 & 0.587 \\
\hline$M C D \times M V A$ & 20 & 0.660 & $0.002^{*}$ \\
\hline$M C D \times M V P$ & 20 & 0.634 & $0.003^{*}$ \\
\hline MVD $\times$ MVA & 20 & -0.102 & 0.670 \\
\hline MVD x MVP & 20 & -0.067 & 0.779 \\
\hline$M V A \times M V P$ & 20 & 0.950 & $<0.001^{*}$ \\
\hline \multicolumn{4}{|l|}{ Radicular cyst } \\
\hline$M C D \times M V D$ & 20 & 0.187 & 0.429 \\
\hline$M C D \times M V A$ & 20 & 0.179 & 0.450 \\
\hline$M C D \times M V P$ & 20 & 0.209 & 0.376 \\
\hline$M V D \times M V A$ & 20 & -0.165 & 0.488 \\
\hline MVD x MVP & 20 & 0.006 & 0.980 \\
\hline$M V A \times M V P$ & 20 & 0.914 & $<0.001^{*}$ \\
\hline \multicolumn{4}{|c|}{ Residual radicular cyst } \\
\hline$M C D \times M V D$ & 20 & -0.018 & 0.941 \\
\hline$M C D \times M V A$ & 20 & -0.306 & 0.190 \\
\hline$M C D \times M V P$ & 20 & -0.079 & 0.740 \\
\hline$M V D \times M V A$ & 20 & 0.057 & 0.810 \\
\hline$M V D \times M V P$ & 20 & 0.134 & 0.573 \\
\hline$M V A \times M V P$ & 20 & 0.713 & $<0.001^{*}$ \\
\hline
\end{tabular}




\section{Discussion}

Despite their high prevalence, the etiopathogenesis and the exact growth and expansion mechanisms of inflammatory odontogenic cysts remain poorly understood. However, it is known that several different types of cells, including mast cells, can participate in such phenomena. ${ }^{19}$ Mast cells are immunoregulatory cells with several cytoplasmic granules and associated with immediate and late immune responses that have been linked to the development, growth, and expansion of periapical inflammatory lesions. ${ }^{18,20,21,22}$ Antibodies against the constituents of these protein granules (such as tryptase or chymase) or against their cell surface receptors (such as CD117-c-KIT) are used for the immunohistochemical detection of tissue mast cells. ${ }^{23}$

In the present study, the MCD index progressively increased from the IDC to RRC and RC. These results corroborate those evidenced by other authors who demonstrated greater immunolabeling in RC compared to IDC and in IDC in relation to their non-inflammatory counterpart. ${ }^{6,19}$ According to Netto et al., ${ }^{19}$ the higher concentration of mast cells observed in inflammatory lesions could indicate their participation in the inflammatory response associated with odontogenic lesions. The higher MCD in RCs seems to be due to the active presence of a constant source of antigenic stimulation caused by bacterial toxins involving a greater variety of immunological cell types, including mast cells. ${ }^{24}$ Considering the findings obtained with RRCs, we believe in the persistence of other antigenic stimuli in the RC area, which maintain the inflammatory infiltrate and facilitate the cystic growth process. ${ }^{25}$

In disagreement with other studies, tryptase-positive mast cells were detected mostly in lesions with a mild/moderate inflammatory infiltrate. ${ }^{19,24,26}$ It is known that mast cells synthesize and release certain prostaglandins and leukotrienes that together contribute to the immediate inflammatory response. Because of mast cell activation, other inflammatory cells are recruited and activated, and a cascade of inflammatory mediator production and release is activated ${ }^{27}$. In this perspective, we consider that lesions with inflammatory infiltrate grade III present different cell types due to the chronicity of the inflammatory process, consequently triggering an adaptive immune response.

MVD provides a quantitative measure of angiogenesis, which has been previously determined in a variety of pathological processes. Pan-endothelial immunohistochemical markers, such as CD34, are applied to obtain MVD, which stain preexisting and newly formed blood vessels. ${ }^{18}$ CD105 (endoglin) is predominantly expressed in endothelial cells present in reactive and neoplastic tissues, in such a way that all are submitted to active angiogenesis. ${ }^{28}$ Because CD105 has specificity for labeling newly formed vessels and the present study aimed to evaluate the general vascular pattern of the lesions, CD34 was chosen as a marker. In addition, Jamshidi et al. ${ }^{29}$ demonstrated poor CD105 immunoblotting in DCs, probably due to their indolent biological behavior and low recurrence rates.

Similar to the results reported by Lima et al., ${ }^{18}$ the RC cases analyzed in the present study exhibited the highest MCD and MVA indexes. Such findings suggest that mast cells are also involved in vascular compartment maintenance in these cystic lesions, corroborating previous studies that attribute angiogenic properties to mast cell tryptase.

Considering the intensity of the inflammatory infiltrate, higher MVD were observed in specimens classified as grade III (intense) compared to the other two categories. These results are similar to those reported by Zizzi et al., ${ }^{16}$ who suggested that the inflammatory infiltrate plays an important role in neoangiogenesis and, consequently, in RC development and growth. The proangiogenic role of mast cells was shown in a study carried out by de Souza Júnior et al. ${ }^{30}$ where they interacted directly with endothelial cells, resulting in the release of angiogenic factors, which then accelerated in vitro vascular neoformation. In addition, the authors demonstrated that the conditioned medium of a co-culture of these two cell types contains the necessary factors to stimulate the angiogenesis process.

Higher scores for MVA and MVP were detected in RC specimens. In a previous study carried out by Lima et al., ${ }^{18}$ most blood vessels marked with CD105 displayed greater vascular lumen, were 
generally associated with cellular areas, and contained a loose perivascular connective tissue. On the other hand, numerous tiny vessels were also immunolabelled with CD34 within the fibrous stroma of both RC and periapical granulomas.

Intermediate scores for MVA and MVP were observed for IDCs in comparison to the other cysts evaluated. However, both parameters correlated with MCD in this type of cyst. Published studies with IDCs are quite scarce especially those that address the vascular events present in this type of cyst. El-Labban and Aghabeigi ${ }^{31}$ demonstrated that DC blood vessels have endothelial lining ruptures and the presence of cell membrane fragments in the space between endothelial cells. However, the authors do not report the diameter of such structures. The positive correlations observed between MCD and both MVA and MVP suggest that mast cells also play an important role in angiogenesis of IDCs, contributing to their growth and expansion. Such results are essential to better understand these cysts, since published studies are quite rare.

In addition, the three assessed lesions displayed a positive correlation between MVA and MVP. In general, this result was expected, since these morphological parameters are related and complement each other concerning vascular structure.

No differences were found between IDCs, RCs, and RRCs in thickness of the epithelial lining. Previous studies also did not detect differences in epithelial lining thickness among types of cystic. ${ }^{25,32,33}$ Although inflammation is a common feature of the studied lesions, we believe that these results are due to biological behavior variations and exposure to antigenic stimuli, which influence the mitogenic potential of the cystic epithelium.

On the other hand, a higher MVP was identified in lesions lined by hyperplastic epithelium. The state of the cystic epithelium has been suggested as a reliable histological parameter of biological activity and/or inactivity for the growth of such lesions. ${ }^{17}$ Since keratinocyte division must occur during cystic growth, it is assumed that lesions with hyperplastic epithelium would be more active than those lined with atrophic epithelium. ${ }^{34}$ Thus, we suggest that the vascular dilatation observed in the studied cases was due to the increase in tissue metabolism and nutrition requirement of the proliferating epithelium. Considering that mast cells can release cytokines, such as IL-1, which induces epithelial proliferation, ${ }^{35}$ our results also indicate that these cells are involved in cystic growth stage.

\section{Conclusions}

Taken together, the results of the present study suggest that tryptase-positive mast cells might play an important role in the angiogenic activity of IDCs, while RCs presented the highest indexes, probably due to the active and constant presence of an antigenic stimulation source. Our findings also confirmed that the intensity of the inflammatory infiltrate and epithelial thickness influence angiogenesis.

\section{References}

1. Shear M, Speight PM. Cysts of the oral and maxillofacial region. 4th ed. Oxford; 2007.

2. de Souza LB, Gordón-Núñez MA, Nonaka CF, Medeiros MC, Torres TF, Emiliano GB. Odontogenic cysts: demographic profile in a Brazilian population over a 38-year period. Med Oral Patol Oral Cir Bucal. 2010 Jul;15(4):e583-90. https://doi.org/10.4317/medoral.15.e583

3. Ochsenius G, Escobar E, Godoy L, Peñafiel C. Odontogenic cysts: analysis of 2,944 cases in Chile. Med Oral Patol Oral Cir Bucal. 2007 Mar;12(2):E85-91.

4. Tsai CH, Weng SF, Yang LC, Huang FM, Chen YJ, Chang YC. Immunohistochemical localization of tissue-type plasminogen activator and type I plasminogen activator inhibitor in radicular cysts. J Oral Pathol Med. 2004 Mar;33(3):156-61. https://doi.org/10.1111/i.0904-2512.2004.00133.x

5. Dimitroulis G, Curtin J. Massive residual dental cyst: case report. Aust Dent J. 1998 Aug;43(4):234-7. https://doi.org/10.1111/j.1834-7819.1998.tb00165.x

6. Kouhsoltani M, Moradzadeh Khiavi M, Jamali G, Farnia S. Immunohistochemical assessment of mast cells and small blood vessels in dentigerous cyst, odontogenic keratocyst, and periapical cyst. Adv Pharm Bull. 2015 Dec;5 Suppl 1:637-41. https://doi.org/10.15171/apb.2015.086 
Involvement of tryptase-positive mast cells and angiogenesis in the growth of inflammatory odontogenic cysts

7. Benn A, Altini M. Dentigerous cysts of inflammatory origin: a clinicopathologic study. Oral Surg Oral Med Oral Pathol Oral Radiol Endod. 1996 Feb;81(2):203-9. https://doi.org/10.1016/S1079-2104(96)80416-1

8. Dohlsten M, Sjögren HO, Carlsson R. Histamine acts directly on human T cells to inhibit interleukin-2 and interferon-gamma production. Cell Immunol. 1987 Oct;109(1):65-74. https://doi.org/10.1016/0008-8749(87)90292-9

9. Marçal JR, Samuel RO, Fernandes D, de Araujo MS, Napimoga MH, Pereira SA, et al. T-helper cell type 17/regulatory T-cell immunoregulatory balance in human radicular cysts and periapical granulomas. J Endod. 2010 Jun;36(6):995-9. https://doi.org/10.1016/i.joen.2010.03.020

10. Ribatti D, Crivellato E. Mast cells, angiogenesis, and tumour growth. Biochim Biophys Acta. 2012 Jan;1822(1):2-8. https://doi.org/10.1016/j.bbadis.2010.11.010

11. Ribatti D, Crivellato E, Roccaro AM, Ria R, Vacca A. Mast cell contribution to angiogenesis related to tumour progression. Clin Exp Allergy. 2004 Nov;34(11):1660-4. https://doi.org/10.1111/j.1365-2222.2004.02104.x

12. Crivellato E, Nico B, Ribatti D. Mast cells and tumour angiogenesis: new insight from experimental carcinogenesis. Cancer Lett. 2008 Sep;269(1):1-6. https://doi.org/10.1016/i.canlet.2008.03.031

13. Kashyap B, Reddy PS, Nalini P. Reactive lesions of oral cavity: a survey of 100 cases in Eluru, West Godavari district. Contemp Clin Dent. 2012 Jul;3(3):294-7. https://doi.org/10.4103/0976-237X.103621

14. Noyan U, Yilmaz S, Arda O, Kuru B. The ultrastructural examination of gingival fibromatosis. J Marmara Univ Dent Fac. 1994 Sep;2(1):409-13.

15. Seifi S, Shafaie S, Ghadiri S. Microvessel density in follicular cysts, keratocystic odontogenic tumours and ameloblastomas. Asian Pac J Cancer Prev. 2011;12(2):351-6.

16. Zizzi A, Aspriello SD, Ferrante L, Stramazzotti D, Colella G, Balercia P, et al. Immunohistochemical correlation between microvessel density and lymphoid infiltrate in radicular cysts. Oral Dis. 2013 Jan;19(1):92-9. https://doi.org/10.1111/i.1601-0825.2012.01961.x

17. Moreira PR, Santos DF, Martins RD, Gomez RS. CD57+ cells in radicular cyst. Int Endod J. 2000 Mar;33(2):99-102. https://doi.org/10.1046/i.1365-2591.2000.00276.x

18. Lima SC, Rizo VH, Silva-Sousa YT, Almeida LY, Almeida OP, León JE. Immunohistochemical evaluation of angiogenesis and tryptasepositive mast cell infiltration in periapical lesions. J Endod. 2011 Dec;37(12):1642-6. https://doi.org/10.1016/i.joen.2011.08.024

19. Netto JNNS, Pires FR, Fonseca EC, Silva LE, Lourenço SQC. Evaluation of mast cells in periapical cysts, dentigerous cysts, and keratocystic odontogenic tumors. J Oral Pathol Med. 2012 Sep;41(8):630-6. https://doi.org/10.1111/j.1600-0714.2012.01126.x

20. Rodini CO, Batista AC, Lara VS. Comparative immunohistochemical study of the presence of mast cells in apical granulomas and periapical cysts: possible role of mast cells in the course of human periapical lesions. Oral Surg Oral Med Oral Pathol Oral Radiol Endod. 2004 Jan;97(1):59-63. https://doi.org/10.1016/S1079-2104(03)00378-0

21. Ajuz NC, Antunes H, Mendonça TA, Pires FR, Siqueira Junior JF, Armada L. Immunoexpression of interleukin 17 in apical periodontitis lesions. J Endod. 2014 Sep;40(9):1400-3. https://doi.org/10.1016/i.joen.2014.03.024

22. Bracks IV, Armada L, Gonçalves LS, Pires FR. Distribution of mast cells and macrophages and expression of interleukin- 6 in periapical cysts. J Endod. 2014 Jan;40(1):63-8. https://doi.org/10.1016/i.joen.2013.09.037

23. Drazić R, Sopta J, Minić AJ. Mast cells in periapical lesions: potential role in their pathogenesis. J Oral Pathol Med. 2010 Mar;39(3):257-62. https://doi.org/10.1111/j.1600-0714.2009.00870.x

24. Andrade AL, Santos EM, Carmo AF, Freitas RA, Galvão HC. Analysis of tryptase-positive mast cells and immunoexpression of MMP-9 and MMP-13 in periapical lesions. Int Endod J. 2017 May;50(5):446-54. https://doi.org/10.1111/iej.12638

25. Martins R, Armada L, Santos TC, Pires FR. Comparative immunoexpression of ICAM-1, TGF- $\beta 1$ and ki- 67 in periapical and residual cysts. Med Oral Patol Oral Cir Bucal. 2017 Jan;22(1):e24-30. https://doi.org/10.4317/medoral.21346

26. Costa Neto H, Andrade AL, Gordón-Núñez MA, Freitas RA, Galvão HC. Immunoexpression of tryptase-positive mast cells in periapical granulomas and radicular cysts. Int Endod J. 2015 Aug;48(8):729-35. https://doi.org/10.1111/iej.12366

27. Coleman JW. Nitric oxide: a regulator of mast cell activation and mast cell-mediated inflammation. Clin Exp Immunol. 2002 Jul;129(1):4-10. https://doi.org/10.1046/i.1365-2249.2002.01918.x

28. Duff SE, Li C, Garland JM, Kumar S. CD105 is important for angiogenesis: evidence and potential applications. FASEB J. 2003 Jun;17(9):984-92. https://doi.org/10.1096/fj.02-0634rev

29. Jamshidi S, Zargaran M, Roshanaei G, Hadadi F, Nazhvani AD. Immunohistochemical comparison of the expression of CD34 and CD105 in odontogenic keratocyst and dentigerous cyst. J Dent (Shiraz). 2017 Mar;18(1):43-6.

30. Souza Júnior DA, Mazucato VM, Santana AC, Oliver C, Jamur MC. Mast cells interact with endothelial cells to accelerate in vitro angiogenesis. Int J Mol Sci. 2017 Dec;18(12):E2674. https://doi.org/10.3390/ijms18122674

31. el-Labban NG, Aghabeigi B. A comparative stereologic and ultrastructural study of blood vessels in odontogenic keratocysts and dentigerous cysts. J Oral Pathol Med. 1990 Nov;19(10):442-6. https://doi.org/10.1111/j.1600-0714.1990.tb00784.x

32. Santos PP, Nonaka CF, Pinto LP, Souza LB. Immunohistochemical expression of mast cell tryptase in giant cell fibroma and inflammatory fibrous hyperplasia of the oral mucosa. Arch Oral Biol. 2011 Mar;56(3):231-7. https://doi.org/10.1016/i.archoralbio.2010.09.020 
33. Lopes CB, Armada L, Pires FR. Comparative expression of CD34, intercellular adhesion molecule-1, and podoplanin and the presence of mast cells in periapical granulomas, Cysts, and Residual Cysts. J Endod. 2018 Jul;44(7):1105-9. https://doi.org/10.1016/i.joen.2018.04.013

34. Cury VC, Sette PS, Silva JV, Araúio VC, Gomez RS. Immunohistochemical study of apical periodontal cysts. J Endod. 1998 Jan;24(1):36-7. https://doi.org/10.1016/S0099-2399(98)80210-0

35. Sheethal HS, Kn H, Smitha T, Chauhan K. Role of mast cells in inflammatory and reactive pathologies of pulp, periapical area and periodontium. J Oral Maxillofac Pathol. 2018 Jan-Apr;22(1):92-7. https://doi.org/10.4103/jomfp.JOMFP_278_17 